\title{
Desenvolvimento de grés porcelânico com incorporação de argilas colombianas submetidas a um processo de branqueamento
} \author{
Juan B. Carda Castelló ${ }^{4}$ \\ ${ }^{1}$ Universidad Nacional de Colombia, Sede Bogotá, Colômbia \\ ${ }^{2}$ Cerámica San Lorenzo Industrial de Colombia S.A, Sopó, Colômbia \\ ${ }^{3}$ Escuela Superior de Cerámica de l'Alcora, Castellón, Espanha \\ ${ }^{4}$ Grupo de Investigación Química del Estado Sólido, Universitat Jaume I, Castellón, Espanha \\ e-mail: carda@uji.es
}

Yudi Ester Ramírez Calderón ${ }^{1}$, Carlos Alberto Nieto Rangel ${ }^{2}$, Jorge Llop Pla ${ }^{3}$, Ester Barrachina Albert ${ }^{4}$

\begin{abstract}
Resumo:
O objetivo do trabalho foi o desenvolvimento de massas de grés porcelânico com argilas de origem colombiana, com as mesmas características técnicas destes produtos internacionalmente. Foram estudadas diversas matérias-primas entre argilas cauliníticas, feldspatos e pozzolanas procedentes da zona central da Colômbia, das regiões de Cundinamarca e Boyacá. Algumas da matérias-primas possuem óxido de ferro acima de 1\%, sendo então submetidas a processos de beneficiamento físicos e químicos para diminuir a quantidade deste óxido corante. $\mathrm{O}$ método de empilhamento e posterior lixiviação com ácido oxálico teve os melhores resultados com uma redução de $60 \%$ do teor de óxido de ferro. Neste trabalho também foi utilizada uma pozzolana natural da região de Boyacá, com maior fusibilidade e reatividade em comparação a um feldspato colombiano. Foi estudada a adição de fundentes como nefelina-sienita e vidro reciclado. Com estas matérias-primas foram desenvolvidas composições de grés porcelânico, obtendo-se valores de absorção de água inferiores a 0,5\%, em temperaturas compreendidas entre 1180 e $1200{ }^{\circ} \mathrm{C}$.
\end{abstract}

Palavras-chave: Grés porcelânico; Matérias-primas; Resíduos; Composições cerâmicas; Beneficiamento.

\section{Introdução:}

Durante os últimos anos, o grés porcelânico é o produto que mais cresce no mercado internacional de materiais de revestimento cerâmico devido principalmente a suas características técnicas e sua constante evolução estética. Com relação à Colômbia, o mercado de grés porcelânico centra-se principalmente na importação deste produto, como se pode observar nas cifras de importação, de $866.359 \mathrm{~m}^{2}$ em 2000 a $19.942 .525 \mathrm{~m}^{2}$ em 2013, com um crescimento médio anual de $32 \%$. Apesar do grande potencial de vendas que a Colômbia tem para este tipo de produto, este não é produzido no país em grande quantidade, devido principalmente à ausência ou pequena presença de matérias-primas colombianas com características técnicas para o seu desenvolvimento.

Dentre as características técnicas que as matérias-primas para o desenvolvimento de grés porcelânico devem cumprir podem ser ressaltadas duas: a primeira é um elevado grau de brancura (ou alvura), pois o mercado busca uma coloração clara; a segunda é um elevado grau de sinterização, pela necessidade de se obter baixa porosidade no produto acabado. Internacionalmente não são muitas matérias-primas que atendem a estas características, tendo sido realizadas diversas pesquisas neste sentido [1-6] com a finalidade de estudar e caracterizar matérias-primas locais, sendo desenvolvidas formulações de massa de grés porcelânico em composições de elevada gresificação e baixa porosidade.
Em muitos casos estas matérias-primas possuem alta quantidade de óxido de ferro, sendo então submetidas a tratamento e condicionamentos utilizando diferentes técnicas, tanto físicas como químicas, para reduzir a quantidade deste óxido corante [7-23]. Os resultados experimentais mostram uma grande melhora na cor do produto final, resultando em materiais cerâmicos de grande brancura. Com relação à obtenção de um alto grau de sinterização foram feitos estudos com incorporação de resíduos às massas de grés porcelânico, como escória de alto forno, escórias metalúrgicas, resíduos de vidro e da indústria cerâmica, entre outros. Os resultados mostram que o uso destes materiais aporta a fusibilidade complementar ao feldspato e pode reduzir a temperatura de sinterização.

Neste sentido, considerando o crescimento do grés porcelânico no mercado de revestimentos cerâmicos, e frente a uma demanda tão competitiva em relação aos preços e com novas empresas no setor, as indústrias cerâmicas colombianas devem levar ao mercado inovação e diferenciação. Portanto, o propósito geral deste estudo foi o desenvolvimento de um grés porcelânico com argilas colombianas, mantendo-se constantes as características técnicas requeridas aos produtos comercializados como baixa absorção de água, alta resistência mecânica e melhor grau de brancura, sendo consideradas distintas matérias-primas disponíveis na indústria cerâmica, que foram submetidas a processos de beneficiamento para serem usadas em massas de grés porcelânico de cor clara. Também foram usados materiais fundentes. 


\section{Materiais e métodos}

As matérias-primas utilizadas pertencem a diferentes unidades geológicas dos estados de Cundinamarca e Boyacá (Colômbia). Algumas destas argilas já são utilizadas na fabricação de bases cerâmicas de coloração vermelha. Entre estas matérias-primas encontram-se duas argilas cauliníticas denominadas como AO e AT, uma pozzolana natural identificada como $\mathrm{PZ}$ e um feldspato $\mathrm{FD}$, além de dois fundentes, nefelina-sienita, identificada como NF, e vidro reciclado, identificado com VR.

As matérias-primas com teores de ferro acima de 1\% foram submetidas a três tratamentos para seu beneficiamento, para reduzir o teor deste óxido corante e assim serem utilizadas na formulação de bases de grés porcelânico de coloração clara. Os três tratamentos foram peneiramento, sedimentação e lixiviação. O peneiramento foi realizado a úmido utilizando duas peneiras de 100 e $150 \mu \mathrm{m}$. Foram preparadas barbotinas de cada uma das matérias-primas com teores de sólido e água de $50 / 50 \%$ e $0,58 \%$ de defloculante, utilizando um agitador mecânico de laboratório durante $30 \mathrm{~min}$. A técnica de sedimentação livre foi realizada em provetas de $500 \mathrm{~mL}$ com tempo de sedimentação de 120 min. Para a separação da fração sólida suspensa foi utilizado um sifão. Para o método de lixiviação foi simulado um processo em pilhas, usando $5 \mathrm{~kg}$ de cada matéria-prima que formaram quatro pilhas de tratamento, uma para cada matéria-prima, fazendo-se um gotejamento por aspersão de solução de ácido oxálico a $0,4 \mathrm{~m}$ por 60 dias, tempo utilizado para maturação de argilas exploradas em minas. Durante a primeira semana as pilhas não foram movidas. Depois deste tempo as pilhas foram movidas mecanicamente para permitir ventilação e homogeneização.

Ao fim dos tratamentos de beneficiamento as matérias-primas com melhores resultados em relação à diminuição de ferro foram selecionadas, com as quais foram desenvolvidas formulações de grés porcelânico considerando-se que seriam aptas em cada etapa do processo cerâmico. Cada formulação foi moída em um moinho planetário com teores de sólido e água de 60 e $40 \%$, respectivamente, e $0,7 \%$ de defloculante, até se obter um resíduo inferior a $1 \%$ em massa na malha de $63 \mu \mathrm{m}$. As barbotinas obtidas de cada composição foram secas e trituradas, em seguida umectadas a $7 \%$ de água em base seca e prensadas uniaxialmente a $30 \mathrm{MPa}$ durante $3 \mathrm{~s}$ em uma prensa Nannetti SS/EA com molde retangular de $30 \times 80 \mathrm{~mm}$. As peças conformadas foram secas novamente em estuda a $110{ }^{\circ} \mathrm{C}$ e então queimadas em um forno gradiente de seis câmaras Nannetti GR98, cada câmara a uma temperatura diferente, nas temperaturas de $1100,1120,1140,1160,1180$ e $1200^{\circ} \mathrm{C}$. Este mesmo procedimento foi realizado para caracterização de cada uma das matérias-primas.

As técnicas instrumentais de caracterização, tanto para as matérias-primas quanto para composições, foram: Análise química por fluorescência de raios X, utilizando um espectrômetro FRX Bruker S4 Explorer. Análise mineralógica por difração de raios $\mathrm{X}$ em um difratômetro Bruker AXS D4 Endeavour, em intervalo $2 \theta$ variável e passo de $0.05^{\circ} / 3 \mathrm{~s}$, pelo método de distribuição de amostras em pó ao acaso. Os parâmetros colorimétricos foram medidos em um espectrofotômetro Konica Minolta CM 3600d com iluminante D65 e observador padrão a $10^{\circ}$. As coordenadas cromáticas utilizadas correspondem ao sistema CIEL*a*b*.

\section{Resultados e discussão}

\subsection{Caracterização das matérias-primas}

\subsubsection{Análise química e mineralógica}

Na Tabela 1 é mostrada, em \% em massa, a composição química de cada uma das matérias-primas. Na Tabela 2 é mostrada sua composição mineralógica. Pode-se observar que a argila AT e o feldspato FD apresentam alto teor em $\mathrm{SiO}_{2}$, relacionado a grande quantidade de quartzo, reduzindo sua reatividade com a temperatura. $\mathrm{A}$ argila $\mathrm{AO}$ contém ilita, o que lhe confere plasticidade e reatividade com temperatura. A argila AT e a pozzolana PZ têm teor de ferro maior que $1 \%$, razão pela qual foram submetidas a processos de beneficiamento para diminuir este valor. Os materiais fundentes, feldspato e pozzolana, têm quantidades semelhantes de óxidos alcalinos $\left(\mathrm{Na}_{2} \mathrm{O}\right.$ e $\left.\mathrm{K}_{2} \mathrm{O}\right)$, bem como composições mineralógicas semelhantes. A nefelina-sienita e o vidro reciclado têm elevado teor de $\mathrm{Na}_{2} \mathrm{O}$, em especial o vidro, que também apresenta baixo teor de $\mathrm{Al}_{2} \mathrm{O}_{3}$, o que indica maior fusibilidade.

\subsubsection{Digramas de gresificação}

Os diagramas de gresificação são curvas dependentes da temperatura que relacionam a absorção de água e a retração linear de materiais cerâmicos, nos quais a retração máxima coincide com a mínima absorção de água na temperatura ótima de queima. A Figura 1 mostra os diagramas de gresificação de cada uma das matérias-primas. Neles pode-se observar que a argila $\mathrm{AO}$ apresenta a menor absorção de água, abaixo de $2 \%$,

Tabela 1. Análise química por fluorescência de raios $\mathrm{X}$ das matérias-primas

\begin{tabular}{|c|c|c|c|c|c|c|c|c|c|c|c|}
\hline MP, \% & $\mathrm{SiO}_{2}$ & $\mathrm{Al}_{2} \mathrm{O}_{3}$ & $\mathrm{Fe}_{2} \mathrm{O}_{3}$ & $\mathrm{TiO}_{2}$ & $\mathrm{~K}_{2} \mathrm{O}$ & $\mathrm{Na}_{2} \mathrm{O}$ & MgO & $\mathrm{CaO}$ & $\mathrm{P}_{2} \mathrm{O}_{5}$ & $\mathrm{SO}_{3}$ & P.F. \\
\hline $\mathrm{AO}$ & 62,6 & 23,3 & 0,5 & 0,9 & 3,0 & 0,2 & 1,6 & $<0,1$ & $<0,1$ & 0,0 & 7,9 \\
\hline AT & 76,6 & 13,5 & 1,5 & 0,8 & 0,8 & 0,1 & 0.4 & 0,1 & 0,1 & 0,0 & 6,1 \\
\hline FD & 76,1 & 14,3 & 0,1 & 0,1 & 4,8 & 3,7 & $<0,1$ & 0,5 & 0,0 & 0,0 & 0,4 \\
\hline PZ & 67,3 & 17,1 & 2,9 & 0,4 & 4,8 & 3,9 & 0,2 & 0,2 & 0,1 & 0,3 & 2,8 \\
\hline $\mathrm{NF}$ & 55,9 & 24,5 & 0,2 & 0,2 & 9,1 & 7,9 & 0,2 & 1,1 & $<0,1$ & 0,1 & 0,6 \\
\hline VR & 70,7 & 1,3 & 0,1 & 0,1 & 0,3 & 13,8 & 3,6 & 9,6 & $<0,1$ & 0,2 & 0,3 \\
\hline
\end{tabular}


a $1200^{\circ} \mathrm{C}$, em comparação com a argila $\mathrm{AT}$, que mostra um comportamento mais refratário.

Em relação aos materiais fundentes, a pozzolana tem um comportamento mais reativo, tornando-a mais sensível à variação de temperatura, com absorção de água abaixo de $0,5 \%$ a partir de $1160^{\circ} \mathrm{C}$ em comparação ao feldspato, que entre 1100 e $1140{ }^{\circ} \mathrm{C}$ atua como material não plástico e a $1160^{\circ} \mathrm{C}$ apresenta uma mudança brusca nas propriedades pois tem seu ponto de sinterização nesta temperatura. Acima desta temperatura apresenta comportamento fundente, com absorção de água menor que $0,5 \%$ a $1200^{\circ} \mathrm{C}$.

Tabela 2. Análise mineralógica por difração de raios $X$ das matérias-primas

\begin{tabular}{cl}
\hline MP & \multicolumn{1}{c}{ Comp. Mineralógica } \\
\hline AO & Quartzo, caulinita, ilita \\
AT & Quartzo, caulinita \\
PZ & Quartzo, caulinita, albita, microclínio \\
FD & Quartzo, caulinita, albita, ortoclásio \\
\hline
\end{tabular}

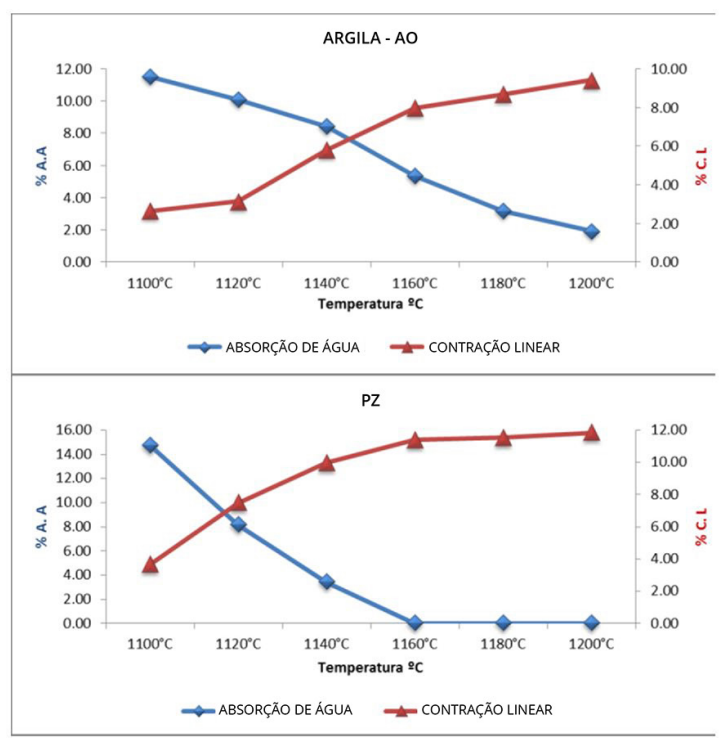

\subsection{Caracterização das matérias-primas beneficiadas}

Como se pode observar pela análise química (Tabela 1), a argila AT e a pozzolana PZ têm teores de óxido de ferro maiores que $1 \%$, valor não usual para matérias-primas usadas na formulação de grés porcelânico. Desta forma, ambas foram submetidas a três tratamentos de beneficiamento (peneiramento a 100 e $150 \mu \mathrm{m}$, sedimentação livre e lixiviação em pilhas) para reduzir o teor deste óxido corante e poder utilizá-las na formulação de bases de grés porcelânico de cor clara. Após o tratamento estas matérias-primas foram caracterizadas quimicamente por fluorescência de raios $\mathrm{X}$ e por colorimetria.

\subsubsection{Análise química}

Como pode ser observado na Tabela 3 o método de lixiviação em pilhas com ácido oxálico foi o de melhor resultado, com maior redução de óxido de ferro entre as matérias-primas. A argila AT sofreu uma diminuição de $30 \%$ no $\mathrm{Fe}_{2} \mathrm{O}_{3}$, pois seu teor passa de 1,5 a $1,1 \%$. Para a pozzolana a diminuição foi de $64 \%$, passando

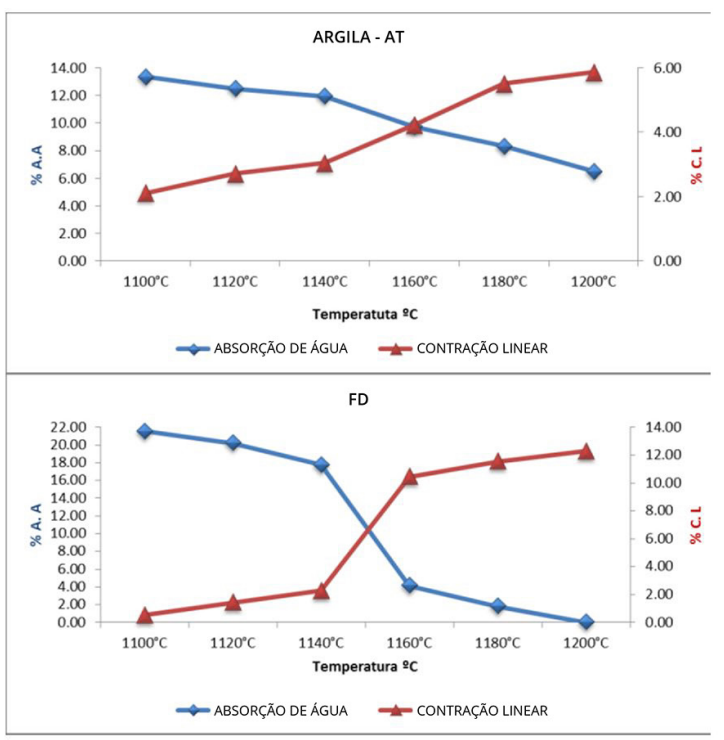

Figura 1. Diagramas de gresificação das matérias-primas

Tabela 3. Análise química das matérias-primas tratadas em cada um dos beneficiamentos

\begin{tabular}{lccccccccccc}
\hline \multicolumn{1}{c}{$\mathbf{M P}, \mathbf{\%}$} & $\mathbf{S i O}_{\mathbf{2}}$ & $\mathbf{A l}_{\mathbf{2}} \mathbf{O}_{\mathbf{3}}$ & $\mathbf{F e}_{\mathbf{2}} \mathbf{O}_{\mathbf{3}}$ & $\mathbf{T i O}_{\mathbf{2}}$ & $\mathbf{K}_{\mathbf{2}} \mathbf{O}$ & $\mathbf{N a}_{\mathbf{2}} \mathbf{O}$ & $\mathbf{M g O}$ & $\mathbf{C a O}$ & $\mathbf{P}_{\mathbf{2}} \mathbf{O}_{\mathbf{5}}$ & $\mathbf{S O}_{\mathbf{3}}$ & $\mathbf{P . F}$ \\
\hline AT original & 74,6 & 15,5 & 1,5 & 0,8 & 0,8 & 0,1 & 0,4 & 0,1 & 0,1 & 0,0 & 6,1 \\
AT $<100 \mu \mathrm{m}$ & 74,0 & 16,0 & 1,5 & 0,7 & 0,0 & 0,1 & 0,4 & 0,1 & 0,1 & 0,0 & 6,2 \\
AT $<150 \mu \mathrm{m}$ & 74,0 & 15,0 & 1,2 & 0,8 & 0,9 & 0,1 & 0,4 & 0,1 & 0,1 & 0,0 & 7,5 \\
AT sedimentado & 73,3 & 16,2 & 1,3 & 0,7 & 0,7 & 0,9 & 0,4 & 0,3 & 0,2 & 0,0 & 6,2 \\
AT lixiviado & 74,6 & 14,8 & 1,1 & 0,8 & 0,9 & 0,1 & 0,3 & 0,1 & 0,1 & 0,0 & 7,2 \\
PZ original & 67,3 & 17,1 & 2,9 & 0,4 & 4,8 & 3,9 & 0,2 & 0,2 & 0,1 & 0,3 & 2,8 \\
PZ <100 $\mu \mathrm{m}$ & 68,0 & 17,3 & 2,2 & 0,2 & 4,8 & 4,5 & 0,0 & 0,3 & 0,1 & 0,1 & 2,7 \\
PZ <150 $\mu \mathrm{m}$ & 68,9 & 17,2 & 2,0 & 0,3 & 4,3 & 4,0 & 0,1 & 0,1 & 0,1 & 0,1 & 2,8 \\
PZ sedimentado & 65,1 & 20,2 & 2,1 & 0,2 & 3,3 & 4,7 & 0,1 & 0,2 & $<0,1$ & $<0,1$ & 3,8 \\
PZ lixiviado & 69,0 & 16,8 & 1,1 & 0,3 & 4,9 & 4,8 & 0,1 & 0,1 & $<0,1$ & 0,1 & 2,8 \\
\hline
\end{tabular}


de 2,9 para $1,1 \%$. Com relação ao peneiramento, para a malha de $150 \mu \mathrm{m}$ a argila AT sofreu uma diminuição de $8,4 \%$ no $\mathrm{Fe}_{2} \mathrm{O}_{3}$ em comparação a $2,6 \%$ para a malha de $100 \mu \mathrm{m}$. A pozzolana tem uma redução de $32,4 \%$ no $\mathrm{Fe}_{2} \mathrm{O}_{3}$ para a malha de $150 \mu \mathrm{m}$ e de $25,4 \%$ para a malha de $100 \mu \mathrm{m}$. No método de sedimentação livre, há uma diminuição no teor de $\mathrm{SiO}_{2}$, um aumento no teor de $\mathrm{Al}_{2} \mathrm{O}_{3}$ e uma redução de $13,8 \%$ no teor de $\mathrm{Fe}_{2} \mathrm{O}_{3}$ para a argila AT e de $27 \%$ para a pozzolana PZ.

\subsubsection{Colorimetria}

A caracterização colorimétrica foi feita com as matérias-primas tratadas quimicamente, por lixiviação, pois foi o tratamento com os melhores resultados para a diminuição do teor de óxido de ferro. Para tanto, as matérias-primas foram submetidas ao mesmo processamento cerâmico e ciclo de queima utilizado na caracterização prévia das MPs. A Tabela 4 mostra as coordenadas cromáticas das MPs originais e daquelas tratadas quimicamente, depois de queimadas a $1180{ }^{\circ} \mathrm{C}$. Pode-se observar que todas as MPs tratadas quimicamente aumentaram significativamente seu grau de alvura, com maior coordenada $L^{*}$ em relação à matéria-prima original.

\subsection{Desenvolvimento das composições}

Para o desenvolvimento das composições de grés porcelânico de cor clara, foram usadas cada uma das matérias-primas anteriormente caracterizadas, incluindo as tratadas quimicamente por ácido oxálico, pois por este método o teor de óxido de ferro foi reduzido a menos de 1\%. Estas composições são mostradas na Tabela 5.

Para identificar o efeito dos tratamentos de beneficiamento foi desenvolvida a composição 1, com o uso das MPs tratadas, e a composição 2, que é a mesma composição 1 , mas com as argilas sem tratamento, para observar a diferença entre as duas. Também foram formuladas composições com outros fundentes que substituem o feldspato, buscando uma maior reatividade a menores temperaturas. As composições foram caracterizadas ceramicamente para se obter a absorção de água e a retração linear das amostras queimadas. Na Figura 2 são mostradas estas propriedades em função da máxima temperatura de queima.

\subsubsection{Diagramas de gresificação}

Ao se observar os diagramas de gresificação (Figura 2) das composições C1 e C2 observa-se que não apresentam diferenças significativas de comportamento, ou seja, o tratamento realizado na argila AT e na pozzolana PZ para seu branqueamento não afeta suas propriedades cerâmicas. As composições não atingem valores inferiores a $0,5 \%$ de absorção de água até a temperatura de $1200{ }^{\circ} \mathrm{C}$ e para esta temperatura não chegam à máxima retração linear.

Nos diagramas de gresificação da composição C3, que contém somente feldspato a $50 \%$, e da composição C4, que contém somente pozzolana a $50 \%$, o comportamento é muito similar ao dos diagramas de cada uma destas matérias-primas. Assim, o uso somente da pozzolana resulta em um comportamento mais reativo que o uso do feldspato, com absorção de água abaixo de $0,5 \%$ a partir de $1160^{\circ} \mathrm{C}$, com grande estabilidade dimensional. A $1160{ }^{\circ} \mathrm{C}$ a composição contendo somente feldspato apresenta uma variação muito brusca das propriedades, pois inicia o processo de sinterização, com menor valor de absorção de água, a $1200^{\circ} \mathrm{C}$.

Os agentes fundentes nefelina-sienita NF e vidro reciclado VR são bastante eficientes quando usados como aditivos nas composições de grés porcelânico, pois reduzem o intervalo de temperatura de queima, como pode ser observado nos diagramas de gresificação para as composições C5 e C6, Figura 2. A partir de $1160{ }^{\circ} \mathrm{C}$ a absorção de água é menor que $0,5 \%$, com boa estabilidade dimensional a partir desta temperatura. Desta forma, o uso destes materiais fundentes reduz em $40{ }^{\circ} \mathrm{C}$ a temperatura de queima em comparação à composição $\mathrm{C} 1$. Durante $\mathrm{a}$ queima, estes materiais fundentes aceleram o processo de densificação, resultando em baixa porosidade aberta e menor absorção de água, com a desvantagem de aumentar a retração linear.

\subsubsection{Colorimetria}

A análise colorimétrica das seis composições desenvolvidas em suas temperaturas ótimas de queima, com base em seus diagramas de gresificação, é mostrada na

Tabela 4. Coordenadas colorimétricas das matérias-primas tratadas e não tratadas processadas a $1180{ }^{\circ} \mathrm{C}$

\begin{tabular}{cccc}
\hline Matéria-prima & Coordenada $\mathbf{L}^{*}$ & Coordenada $\mathbf{a}^{*}$ & ${\text { Coordenada } \mathbf{b}^{*}}^{*}$ \\
\hline AT original & 80,9 & 4,08 & 21,4 \\
AT tratada & 85,2 & 0,92 & 15,1 \\
PZ original & 36,6 & 5,69 & 7,33 \\
PZ tratada & 45,8 & 10,2 & 15,9 \\
\hline
\end{tabular}

Tabela 5. Composições de massa de grés porcelânico

\begin{tabular}{ccccccc}
\hline MP, \% em massa & C1 & C2 & C3 & C4 & C5 & C6 \\
\hline AO & 20 & 20 & 20 & 20 & 10 & 10 \\
AT & 30 & 30 & 30 & 30 & 50 & 50 \\
PZ & 30 & 30 & & 50 & 35 & 35 \\
FD & 20 & 20 & 50 & & 5 & \\
NF & & & & & 5 \\
VR & & & & & & 5 \\
\hline
\end{tabular}



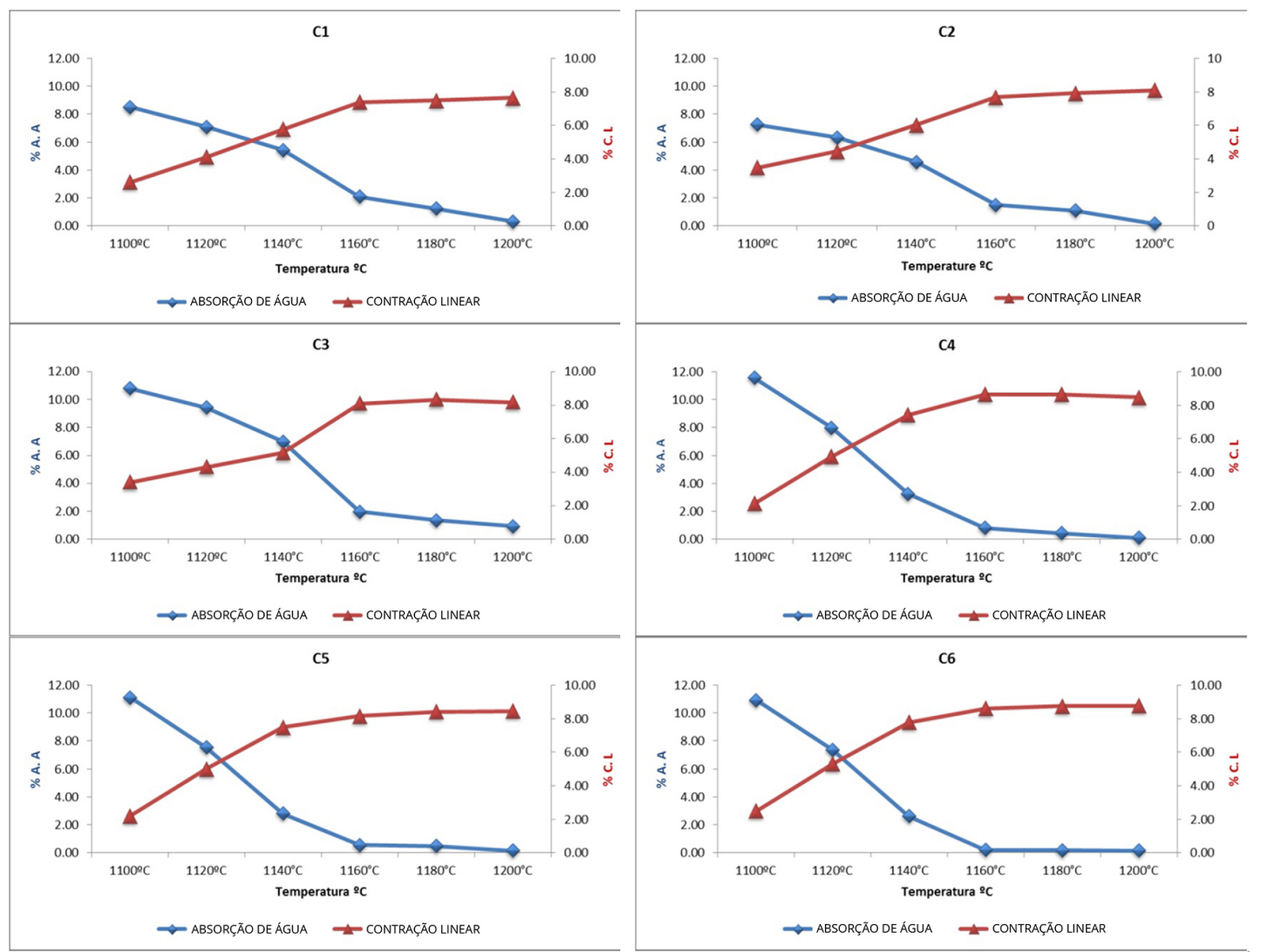

Figura 2. Diagramas de gresificação para as composições propostas

Tabela 6. Coordenadas cromáticas de cada uma das composições

\begin{tabular}{cccc}
\hline Composição & Coordenada $\mathbf{L}^{*}$ & Coordenada $\mathbf{a}^{*}$ & ${\text { Coordenada } \mathbf{b}^{*}}^{*}$ \\
\hline C1 & 71,1 & 1,72 & 15,0 \\
C2 & 60,3 & 3,17 & 12,9 \\
C3 & 74,2 & 2,24 & 13,4 \\
C4 & 65,8 & 3,25 & 18,8 \\
C5 & 65,1 & 4,06 & 20,1 \\
C6 & 65,7 & 6,08 & 22,7 \\
\hline
\end{tabular}

Tabela 6. Há diferença significativa entre a composição 1, formulada com as MPS tratadas, e a composição C2, com as mesmas matérias-primas em iguais teores, mas formulada com as argilas originais sem nenhum tratamento. A coordenada $\mathrm{L}^{*}$ da composição $\mathrm{C} 1$ tem 10,7 pontos acima da composição C2. Portanto, o tratamento aplicado foi eficiente para o desenvolvimento de grés porcelânico de cor clara.

A composição $\mathrm{C} 3$ tem a maior coordenada $L^{*}$ de todas as composições devido principalmente ao uso de feldspato a $50 \%$, de cor branca e com teor de óxido de ferro muito baixo $(0,1 \%)$. Esta composição pode ser comparada com a composição $\mathrm{C} 4$, formulada com $50 \%$ de pozzolana na qual a coordenada $\mathrm{L}^{*}$ é menor. O uso da nefelina-sienita NF e vidro reciclado VR diminui o valor da coordenada $L^{*}$, o que está em consonância com a quantidade de fase vítrea formada durante a etapa de queima, pois, em maior temperatura, maior será a quantidade de elementos cromóforos dissolvidos nesta fase vítrea, o que gera maior coloração.

\section{Conclusões}

I. Foi possível melhorar o grau de brancura da argila AT e da pozzolana PZ com tratamentos de beneficiamento tanto químicos quanto físicos. O melhor resultado foi obtido com o método químico de lixiviação por pilhas com ácido oxálico.

II. Foi possível desenvolver diferentes composições de massas de grés porcelânico com matérias-primas colombianas. 
III. As composições de grés porcelânico desenvolvidas com as matérias-primas tratadas aumentam a brancura, sem alterar os diagramas de gresificação.

IV. O feldspato potássico colombiano foi totalmente substituído por outros fundentes, como uma pozzolana natural, nefelina-sienita e vidro reciclado, reduzindo o intervalo de temperatura de queima e baixando em $40{ }^{\circ} \mathrm{C}$ a máxima temperatura de queima.

V. Neste estudo a pozzolana pode ser considerada um novo material fundente para a fabricação de grés porcelânico, destacando a maior facilidade de obtenção desta em depósitos exploráveis.

VI. As composições de grés porcelânico desenvolvidas mantiveram as mesmas características técnicas para este tipo de produto.

\section{Referências:}

[1] Sánchez Muñoz, L., Nebot Díaz, I., Carda, J. B., Tuduri, F., et al., "Obtención de soportes cerámicos de baja porosidad a partir de materias primas nacionales". Cerámica Información 27 (272) 48-54.

[2] Marciano, J., Coelho, J., et al., "Materias primas para pastas de gres porcelánico en Brasil”. En Memorias del IX Congreso mundial de la calidad del azulejo y del pavimento cerámico, QUALICER. Cámara Oficial de Comercio, Industria y Navegación, Pos $71-73$.

[3] Sousa, M., Freitas, J., et al., "Fabricación de gres porcelánico con materias primas seleccionadas del noroeste de Brasil". En Memorias del IX Congreso mundial de la calidad del azulejo y del pavimento cerámico, QUALICER. Cámara Oficial de Comercio, Industria y Navegación, Pos 239-243.

[4] Abadira, M., Sallamb, E., et al., "Preparation of porcelain tiles from Egyptian raw materials". Ceramics International., 28, 303-310.

[5] Ríos, C. "Uso de materias primas colombianas para el desarrollo de baldosas cerámicas con alto grado de gresificación". Universidad Nacional de Colombia, sede Medellín.

[6] Faten Hammami-Ben Zaie, Riadh Abidi, Najet Slim-Shimi, Alireza K. Somarin. "Potentiality of clay raw materials from Gram area (Northern Tunisia) in the ceramic industry". Applied Clay Science 112-113, 1-9

[7] Barrachina, E., Calvet, I., Fraga, D., Carda, J. B: "Ceramic porcelain stoneware production with Spanish clays purified by means of the removal of iron compounds and organic matter using physical methods". Applied Clay Science 143, 258-264

[8] Pérez Ayala, G., Vargas Rodríguez, Y., Córdoba Tuta, E. "Beneficio de una arcilla caolinítica de la región de Barichara (Santander) para la fabricación de refractarios". Escuela de Ingeniería Metalúrgica y Ciencia de Materiales, Universidad Industrial de Santander.

[9] Muñoz García, A. "Blanqueo de caolines de la Unión Antioquia usando métodos hidroelectrometalúrgicos". Universidad Nacional de Colombia, sede Medellín.

[10] González, J.A., Ruiz, M del C. "Bleaching of kaolins and clays by chlorination of iron and titanium" Applied Clay Science 33, 219-229

[11] Olvera Venegas, P. N., Hernández Cruz, L.E., Lapidus, G. T. "Estudio de la remoción de hierro de una arcilla caolinítica por medio de lixiviación reductiva". Universidad Autónoma del Estado de Hidalgo, Área Académica de Ciencias de la Tierra y Materiales.

[12]P. Orosco, D. Lavarra, E. Perino, M. del C. Ruiz y J. González. "Desferrificación de arcillas de uso en la industria de refractarios" Instituto de Investigaciones en Tecnología Química (INTEQUI-CONICET. Facultad de Química, Bioquímica y Farmacia, Universidad Nacional de San Luis. Carbo San Luis S. A.

[13]Llop, J., Notari, M.D.,Barrachina, E., Nebot, I., Núñez, I.,Carda, J.B. "Tratamientos en arcillas con vistas a mejorar sus coordenadas cromáticas para el proceso de fabricación de gres porcelánico". Bol. Soc. Esp. Ceram. V. 49, 6, 413422.

[14] Guzmán, A., Torres, J., Cedeño, M., Delvasto, S., Amigó, V., Sánchez, E. "Fabricación de gres porcelánico empleando ceniza de tamo de arroz en sustitución del feldespato" Grupo de Investigación de Materiales Compuestos, GMC. Escuela de Ingeniería de Materiales, Universidad del Valle, Cali, Colombia

[15]Quaranta, N.,Caligaris, M., López, H., Unsen, M. Y Lalla, $\mathrm{N}$. "Inclusión de residuos industriales en la producción de materiales cerámicos". Grupo de estudios ambientales, Facultad Regional San Nicolás, Universidad Tecnológica Nacional, Colón 332, San Nicolás-Argentina.

[16] Lázaro, C., Ramón Trilles, V., Gómez, F., Allepuz. S., Fraga, D y Carda J.B. "Incorporación de residuos derivados de la fabricación cerámica y del vidrio reciclado en el proceso cerámico integral". Boletín de la Sociedad Española de Cerámica y Vidrio. Vol 51, 2, 139-144.

[17] Caligaris, R., Quaranta, N., Caligaris, M y Benavidez. E., "Materias primas no tradicionales en la industria cerámica". Bol. Soc. Esp. Cerám. Vidrio, 39 [5] 623-626 